DOI 10.37882/2223-2982.2021.11-2.18

\title{
КОНТРОЛЬ СФОРМИРОВАННОСТИ УЧЕБНЫХ ЗНАНИЙ С ИСПОЛЬЗОВАНИЕМ НЕЗАВИСИМОЙ ЭКСПЕРТИЗЫ
}

\section{CONTROL OF THE FORMATION OF EDUCATIONAL KNOWLEDGE USING INDEPENDENT EXPERTISE}

\author{
S. Levitsky \\ A. Khromova \\ D. Fedotov
}

Summary: The article provides a comparative analysis of the data on the formation of educational knowledge, skills and abilities obtained during an independent assessment of the quality of education and as a result of intermediate certification at a university. The Federal Internet Exam in the Field of Vocational Education was used as an independent assessment tool. On the example of the discipline «Biology», the fourth (highest) level of training was revealed among the first-year students in the specialty 30.05 .01 «Medical Biochemistry» in $82 \%$ of students participating in the federal testing. However, according to the results of the exam during the intermediate certification conducted by the university independently, only $56 \%$ of students reached this level. The authors conclude that at this stage of higher education reform, the use of Federal Internet Exam in the Field of Vocational Education as a tool for independent assessment of the quality of education should be considered appropriate and effective, but it is necessary to improve its methodological component.

Keywords: independent assessment of the quality of education, federal Internet exam in the field of vocational education.
Левицкий Сергей Николаевич

к.б.н., доцент, Северный государственный медицинский университет, г. Архангельск sergeylevitski@yandex.ru

Хромова Анна Владимировна к.м.н., доцент, Северный государственный медицинский университет, г. Архангельск medbio@mail.ru

Федотов Денис Михайлович к.м.н., Северный государственный медичинский университет, г. Архангельск medbio@mail.ru

Аннотация: В статье дается сравнительный анализ данных сформированности учебных знаний, умений и навыков, полученных в ходе независимой оценки качества образования и в результате промежуточной аттестации в вузе. Инструментом независимой оценки выступал Федеральный интернет-экзамен в сфере профессионального образования (ФЭПО). На примере дисциплины «Биология» у обучающихся первого курса по специальности 30.05.01 «Медицинская биохимия» выявлены четвертый (наивысший) уровень обученности у $82 \%$ обучающихся, участвующих в федеральном тестировании. Однако, по результатам экзамена в ходе промежуточной аттестации, проводимом вузом самостоятельно, этого уровня достигли лишь $56 \%$ обучающихся. Авторами делается вывод о том, что на данном этапе реформирования высшего образования использование ФЭП0 как инструмента независимой оценки качества образования следует считать целесообразным и эффективным приемом, однако необходимо усовершенствование его методологической составляющей.

Ключевые слова: независимая оценка качества образования, федеральный интернет-экзамен в сфере профессионального образования.

Одним из примеров внедрения независимой оценки качества образования в вузах является использование проекта «Федеральный интернет-экзамен в сфере профессионального образования» (ФЭПО). Данный проект предлагает разноуровневые модели педагогических измерительных материалов и оценки результатов обучения студентов на основе компетентностного подхода $[4,5]$.

Кроме того, переход системы высшего профессионального образования на федеральные государственные образовательные стандарты нового поколения $(3++)$ требуют изменения подхода к оцениванию результатов обучения $[6,7]$.

Факультет медико-профилактического дела и медицинской биохимии ГБОУ ВО Северный государственный медицинский университет (г. Архангельск) является активным участником данного проекта. 
Целью данного исследования является изучение возможности использования результатов ФЭПО (на примере дисциплины «Биология») в качестве прогностического показателя успешности обучения студентов. Результаты тестирования обучающихся удобны для принятия решений на различных уровнях управления учебным процессом в вузе.

\section{Методы и приншипы исследования}

Были проанализированы результаты ФЭПО по биологии за 2019-2021 г. в сравнении с результатами промежуточной аттестации по данной дисциплине (устный экзамен) у обучающихся первого курса по специальности 30.05.01 «Медицинская биохимия».

Структура экспертной работы по дисциплине «Биология» включала в себя 3 блока: блок 1 (тематическое наполнение) включал в себя 24 темы, которые были определены ответственным преподавателем кафедры медицинской биологии и генетики, где преподается данная дисциплина, блок 2 (модульное наполнение) состоял из 10 модулей, блок 3 (кейс-наполнение) содержал 3 кейса. Первый блок проверял соответствующие знания с известными способами решения, которые демонстрировались в ходе изучения дисциплины. Необходимо выбрать один верный ответ из предложенных. Второй блок включал вопросы на знания и умения. Здесь необходим самостоятельный выбор одного из известных способов решения. Эксперты оценивали как знания по дисциплине, так и умения пользоваться ими при решении типовых задач. Третий блок проверял все типы дидактических единиц: знания, умения, навыки. Блок представлен кейс-заданиями, состоящими из описания практической ситуации и вопросов к ней. Выполнение студентом кейс-заданий требует решения поставленной проблемы (ситуации) в целом и проявления умения анализировать конкретную информацию прослеживать причинно-следственные связи, выделять ключевые проблемы и методы их решения, формировать нетрадиционный способ мышления.

В соответствии с методикой проведения тестирования выделены уровни результатов обучения [8].

Первый уровень: усвоение элементарных знаний. Наличие ошибок и неточностей.

Второй уровень: обладают необходимой системой знаний и владеют некоторыми умениями, способны по- нимать и интерпретировать информацию.

Третий уровень: осознанное владение умениями, навыками и способами деятельности, анализируют, сравнивают и обосновывают выбор методов решения заданий в практико-ориентированных ситуациях.

Четвертый уровень: способны использовать сведения из различных источников для успешного исследования и поиска решения в нестандартных практико-ориентированных ситуациях. Достигнутый уровень обученности определяется по результатам выполнения всего комплекса заданий в соответствии с алгоритмом, разработанным авторами.

\section{Основные результаты}

Анализ результатов ФЭПО показал, что $12 \%$ обучающихся находятся на втором уровне обученности, 6 $\%$ - на третьем уровне, $82 \%$ - на четвертом уровне. В соответствии с моделью оценки результатов обучения процент студентов направления подготовки «Медицинская биохимия» СГМУ на уровне обученности не ниже второго (по дисциплине «Биология» цикла МЕН ФГОС ВО) составил $100 \%$.

Распределение студентов по итогам выполнения заданий по дсциплине «Биология» представлено в таблице 1.

Таким образом, независимая экспертиза путем проведения ФЭПО показала, что более $80 \%$ обучающихся способны обобщать и оценивать информацию, полученную на основе исследования нестандартной ситуации, умеют распознавать биологические процессы, явления и объекты по их описанию, способны добывать и применять дополнительные сведения, сопоставляя их с предложенной ситуацией, самостоятельно и целенаправленно выбирать методы решения биологических задач и проблемных ситуаций.

Сравнительный анализ результатов ФЭПО с результатами промежуточной аттестации по дисциплине «Биология» в виде устного экзамена, включающего теоретические вопросы, решение генетической задачи и диагностику микропрепарата по паразитологии показал следующее (таблица 2).

Таким образом, устный экзамен показал, что около четверти обучающихся не в полной мере умеют устанавливать

Правильность выполнения заданий в блоках

Таблица 1.

\begin{tabular}{|c|c|c|c|}
\hline \% обучающихся, имеющих правильные ответы: & Блок 1 (знания) & Блок 2 (знания, умения) & Блок 3 (знания, умения, навыки) \\
\hline $91-100 \%$ & 41,18 & 17,65 & 29,42 \\
\hline $81-90 \%$ & 23,53 & 64,71 & 35,29 \\
\hline $71-80 \%$ & 29,41 & 5,88 & 23,53 \\
\hline $61-70 \%$ & 5,88 & 11,76 & 11,76 \\
\hline
\end{tabular}


Таблица 2.

Уровень обученности обучающихся по результатам ФЭПО и промежуточной аттестации

\begin{tabular}{|c|c|c|}
\hline Уровень обученности (по ФЭПО) & \% обучающихся (данные ФЭП0) & \% обучающихся (данные промежуточной аттестации) \\
\hline 1 & 0 & 0 \\
\hline 2 & 12 & 22 \\
\hline 3 & 6 & 22 \\
\hline 4 & 82 & 56 \\
\hline
\end{tabular}

последовательность биологических процессов, соотносить отдельные биологические факты и явления, называть характерные признаки биологических явлений и процессов, группировать факты по различным признакам, а часть обучающихся усвоили лишь некоторые элементарные знания основных вопросов по дисциплине и слабо и необходимой системой знаний основных биологических понятий, закономерностей, процессов и явлений, слабо связывают биологические процессы и отдельные факты.

\section{Зак^ючение}

Сравнительный анализ результатов освоения учебной дисциплины «Биология» студентами - биохимиками показал, что независимая оценка, полученная на основе Федерального интернет-экзамена в сфере профессионального образования значительно выше оценки, полученной в ходе промежуточной аттестации. Однозначно причины таких различий сформулировать довольно сложно ввиду маленькой численности выборки обследуемых. Следует отметить, что технологии проведения ФЭПО постоянно усовершенствуются и могут иметь на данный момент методические недостатки. Например, вызывает некоторое сомнение тезис «студент освоил дисциплину, если он усвоил все дидактические единицы (ДЕ)», что противоречит компетентностному подходу в профессиональном образовании $[9,10]$. Однако, на данном этапе реформирования высшего образования использование ФЭПО как инструмента независимой оценки качества образования следует считать целесообразным и эффективным приемом.

\section{ЛИТЕРАТУРА}

1. Матвеев Н.Н., Черных А.С. Особенности проведения федерального интернет-экзамена в сфере профессионального образования при реализации компетентностного подхода по ФГОС / Н.Н. Матвеев// Актуальные направления научных исследований XXI века: теория и практика. - 2013. - № 5. - С. 465-470.

2. Андриенкова Ю.Д., Медведев П.Н., Малий Д.В. К вопросу о независимой оценке качества подготовки обучающихся в вузе /Ю.Д. Андриенкова // Современные проблемы науки и образования. - 2021. - № 2. Режим доступа: URL: http://science-education.ru/ru/article/view?id=30728 (дата 0бращения: 11.06.2021).

3. Тимофеева Н.Н. Федеральный интернет-экзамен в сфере профессионального образования: динамика развития /Н.Н. Тимофеева// Инновации в образовательном процессе. Сборник трудов научно-практической конференции. - 2013. - С. 264-267.

4. Киселева В.П. Оценка результатов обучения студентов по итогам ФЭП0: компетентностный подход /В.П. Киселева// Оценка компетенций и результатов обучения студентов в соответствии с требованиями ФГОС: материалы III Всерос. науч.-практ. конф., Москва. - 2012. - С. 31-34.

5. Япринцева К.Л. Федеральный интернет-экзамен в сфере профессионального образования - инструмент оценки качества сформированности компетенций специалистов /К.Л. Япринцева// В сборнике: Культура - Искусство - Образование. Материалы XXXVIII научно-практической конференции научно-педагогических работников института. - 2017. - С. 248-251.

6. Наводнов В.Г. ФЭПО: ретроспектива и перспективы /В.Г. Наводнов // Аккредитация в образовании. - №7 (123). - 2020. Режим доступа: URL: https://akvobr.ru/fepo_retrospektiva_perspektivy.html (дата обращения: 03.07.2021).

7. Белянская Е.С. Федеральный интернет-экзамен в сфере профессионального образования как независимая оценка качества результатов обучения / Е.С. Белянская// В сборнике: Международная научно-практическая конференция «Медицинские приборы и технологии - 2018». - 2019. - С. 137-140.

8. Единый портал интернет-тестирования B сфере образования. Оценка и мониторинг образовательных достижений студентоB. Режим доступа: URL: https://i-exam.ru/ (дата обращения: 22.05.2021)

9. Гуркова 0.М. Федеральный интернет-экзамен в сфере профессионального образования: «за» и «против» / 0.М. Гуркова// В сборнике: Инновационные тенденции развития российской науки. Материалы IV Международной (заочной) научно-практической конференции молодых ученых. - 2011. - 436-438.

10. Гудимова К.А. Преимущество и недостатки компьютерного тестирования / К.А. Гудимова// Материалы ХІІ Международной студенческой научной конференции «Студенческий научный форум». Режим доступа: URL: https://scienceforum.ru/2020/article/2018019521 (дата обращения: 12.07.2021).

11. Давыдова Н.Г., Левицкий С.Н., Тарасова А.В. Результаты ЕГЭ как инструмент диагностики успешности обучения будущих врачей-стоматологов / Н.Г. Давыдова //Cachedra-Кафедра. Стоматологическое образование. - 2020. - № 72-73. - С. 96-99. 